\title{
Guidelines for the Management of Squamous Cell Carcinoma in Organ Transplant Recipients
}

\author{
Thomas Stasko, MD, ${ }^{*}$ Marc D. Brown, MD, ${ }^{\dagger}$ John A. Carucci, MD, PhD \\ Sylvie Euvrard, MD, ${ }^{\S}$ Timothy M. Johnson, MD, $§$ Roberta D. Sengelmann, MD," \\ Eggert Stockfleth, MD, ${ }^{*}$ And Whitney D. Tope, MPhil, MD, ${ }^{* *}$ For THE \\ InTERnATIONAL TRANSPLANT-SKin CANCER COLlaborATIVE AND \\ The European Skin CARE in Organ Transplant Patients Network
}

*Vanderbilt University School of Medicine, Nashville, Tennessee; ${ }^{\dagger}$ University of Rochester School of Medicine, Rochester, New York; “Weil Medical College of Cornell, New York, New York; ${ }^{\S}$ Department of Dermatology, Edouard Herriot Hospital, Lyons, France; ${ }^{\S}$ University of Michigan Medical School, Ann Arbor, Michigan; ${ }^{\top}$ Washington University School of Medicine, St. Louis, Missouri; "Department of Dermatology, Charité, Berlin, Germany; and ** University of California at San Francisco School of Medicine, San Francisco, California

BACKGROUND. Solid-organ transplant recipients have a high incidence of cutaneous squamous cell carcinoma (SCC) and often develop multiple and aggressive tumors. There are few published studies or reviews, which provide guidance to the clinician in the treatment of these patients.

OBJECTIVE. The objective was to develop useful clinical guidelines for the treatment of skin cancer in organ transplant recipients (OTRs).

METHODS. The members of the Guidelines Committee of the International Transplant-Skin Cancer Collaborative (ITSCC) carried out a computerized search utilizing the databases of the National Library of Medicine for reports in the literature on SCC in OTRs. These reports were collectively examined by the group and combined with experiences from the members' clinical practices in the development of the guidelines.
RESULTS. More than 300 articles relating to SCC in OTRs were reviewed. In general, reports concerning the prevention and treatment of SCC in OTRs are of individual cases or small case series. They are retrospective in nature, statistically nonrigorous, and lack the complete epidemiologic data necessary to derive definitive conclusions. Combining these studies and collective clinical experience, however, is at present the best available method for devising guidelines for the treatment of SCC in OTRs.

CONCLUSION. Guidelines developed for the treatment of skin cancer in OTRs, supported by the best available data and collective clinical experience, may assist in the management of OTRs with SCC. The development of clinical pathways and complete documentation with rigorous prospective study is necessary to improve and refine future guideline development.

THOMAS STASKO, MD, MARC D. BROWN, MD, JOHN A. CARUCCI, MD, PHD, SYLVIE EUVRARD, MD, TIMOTHY M. JOHNSON, MD, ROBERTA D. SENGELMANN, MD, EGGERT STOCKFLETH, MD, AND WHITNEY D. TOPE, MPHIL, MD HAVE INDICATED NO SIGNIFICANT INTEREST WITH COMMERCIAL SUPPORTERS.

DR. STOCKFLETH IS A MEDICAL CONSULTANT FOR 3M AND DR. BROWN IS ON THE SPEAKERS BUREAU FOR 3M.

\section{The International Transplant-Skin Cancer Collaborative and the European Skin Care in Organ Transplant Patients Network}

THE FREQUENCY of aggressive skin cancer in solidorgan transplant recipients led to the formation of the International Transplant-Skin Cancer Collaborative in 2002. At present the membership consists of more than 125 physicians from the Americas and Australia, primarily dermatologists, but open to all specialties. Interaction with other disciplines is actively sought

Address correspondence and reprint requests to: Thomas Stasko, MD, 3900 The Vanderbilt Clinic, Nashville, TN 37232-5227, or e-mail: tom.stasko@vanderbilt.edu. and the organization strives to facilitate and encourage multidisciplinary membership and collaboration. The mission of International Transplant-Skin Cancer Collaborative (ITSCC) is twofold:

1. To integrate and support basic scientific and clinical research to address the special needs of solid-organ transplant recipients with skin cancer to improve quality of care.

2. To educate patients, scientists, primary care doctors, and specialist physicians on the unique needs and clinical care issues in solid-organ transplant patients.

The European Skin Care in Organ Transplant Recipients (SCOP) Network was developed with 
similar goals. The SCOP Network began in December 2000 with national organizations in France, Italy, and Germany and was expanded to a European level in June 2002. In addition, SCOP is developing an Internet-based data registry uniting multiple specialized dermatologic outpatient departments from all parts of Europe. This database will allow the collection of comprehensive epidemiologic data on skin diseases in organ transplants. The data gathered will be used to reevaluate existing strategies of skin cancer prevention as well as to develop new therapeutic options for cancerous and infectious skin diseases.

\section{Background}

Fair-skinned organ transplant recipients (OTRs) develop cutaneous malignancies at rates that have been estimated to be up to 100 times that of the general population. ${ }^{1-3}$ In Norway there is required reporting of all cutaneous malignancies, with the exception of basal cell carcinoma. As a result an accurate general prevalence of nonmelanoma skin cancer (NMSC) in the population is known. Against this background a study of a cohort of kidney and cardiac transplant patients from a single Norwegian center found the rate of squamous cell carcinoma (SCC) to be 65 times that the general population when controlled for age and sex. The risk for melanoma increased 3-fold, Kaposi's sarcoma 84 -fold, and SCC of the lip 20-fold. ${ }^{4}$ Merkel cell carcinoma also appears to be more frequent and aggressive in transplant recipients. ${ }^{5}$ Skin cancers also develop at a younger age in OTRs, often starting 3 to 5 years after transplantation. 6,7 Those OTRs who do develop skin cancers often develop multiple tumors. In a study from Queensland, Australia, the average number of tumors was 7.5 per patient with a standard deviation of 17.5 and $76 \%$ of the patients who had a skin cancer before transplantation developed additional tumors with an average of 16.5 tumors per individual. ${ }^{8}$ Nonmelanoma skin cancers in OTRs can be very aggressive. Data from the Cincinnati Tumor Registry indicated that $5.2 \%$ of all transplant patients died of skin malignancies with $63 \%$ of those deaths coming from SCC. ${ }^{9}$ In a group of Australian heart transplant recipients, skin cancer caused $27 \%$ of the 41 deaths, which occurred 4 or more years after transplantation. ${ }^{10}$

Guidelines for care of NMSC in the general population have been previously published by the National Comprehensive Cancer Network ${ }^{11}$ and the American Academy of Dermatology. ${ }^{12}$ Guidelines for the prevention and treatment of skin cancers in renal transplant patients have been recently published, but are somewhat general in nature. ${ }^{13}$ There are no large- scale, long-term studies available that address the care of SCC in OTRs. The goal of the Guidelines Committee of the ITSCC is to develop guidelines for the treatment of skin cancer in OTRs, supported by the best available data and collective clinical experience, to assist in the management of these patients. The development of clinical pathways and complete documentation may also be useful for development of prospective database trials for future guideline revisions.

\section{Screening and Education}

Patients should receive a skin cancer-oriented history and physical before transplantation if practical. All patients should be given education regarding sun exposure and the recognition of premalignant and malignant skin lesions in high-risk patients should be identified for closer follow-up.

The initial skin exam should include a detailed history with an emphasis on skin cancer, sun exposure, and warts and a family history of skin cancer. All OTRs are considered to be at increased risk for the development of skin cancer; however, several factors indicate a higher degree of susceptibility within this group. These factors include:

1. History of skin cancer. ${ }^{9}$

2. History of actinic keratoses. ${ }^{7}$

3. Fair skin (Fitzpatrick types I-III). ${ }^{14}$

4. History of chronic sun exposure and/or sun burns. ${ }^{9,15,16}$

5. Older age. ${ }^{17-20}$

6. Duration and intensity of immunosuppression. ${ }^{17,20-22}$

7. History of human papillomavirus infection. ${ }^{23,24}$

8. CD4 lymphocytopenia. ${ }^{25}$

The patient should be examined for the presence of actinic damage, human papillomavirus infection, premalignant lesions, and skin malignancies (Figure 1).

OTRs should receive extensive education about the risk of developing skin cancer and its associated morbidity and mortality. They should be educated concerning sun protection including avoidance of sun exposure, the wearing of protective clothing and the use of effective UVB/UVA sunscreens with an effectively high sun protection factor ( 15 or higher in the United States) to all sun exposed areas on a daily basis. $^{26-28}$ Tanning bed use should be prohibited. It is unknown whether the use of other prophylactic measures (topical retinoids, topical 5-fluorouracil, chemical peel, etc.) before the development of precancerous and cancerous lesions will retard their development. Education should be repeated at regular 


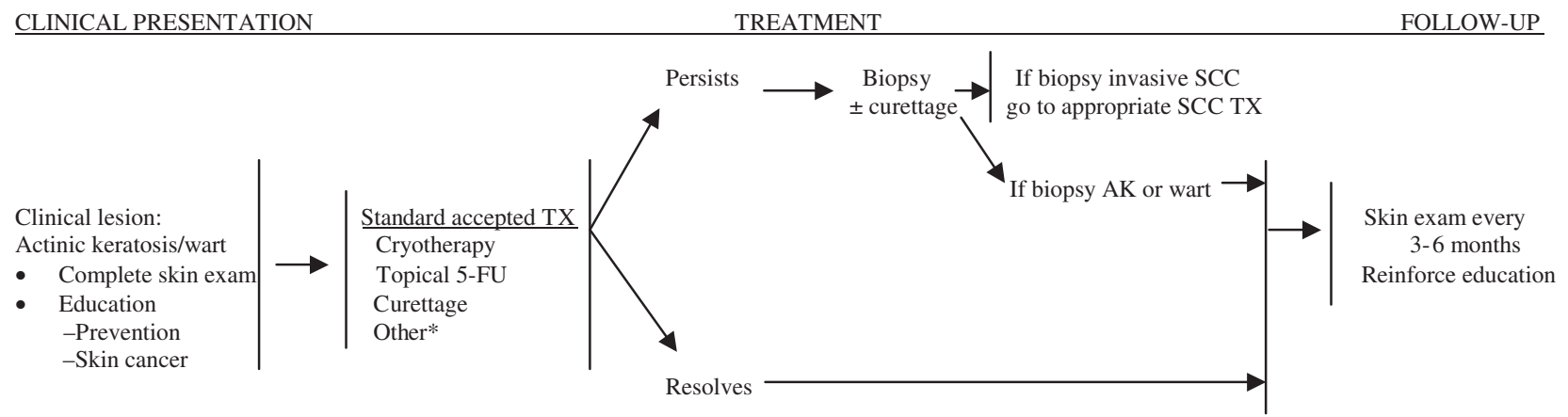

*Other potential TX for select cases includes topical imiquimod, photodynamic therapy, laser/chemical peel/dermabrasion, topical/systemic retinoids, and excision

Figure 1. Management of actinic keratosis and warts in OTRs.

intervals to maintain its effectiveness. ${ }^{29-31}$ Owing to the high prevalence and associated morbidity and mortality of skin cancer in OTRs, patients should receive education before transplantation regarding the risk of developing skin cancer. To enhance early detection and treatment OTRs should be educated in the clinical appearance of common benign, premalignant, and malignant neoplastic skin lesions. OTRs should be taught self-examination of the skin for early detection of malignant and premalignant lesions. Each OTR should then be examined at appropriate time intervals determined by the individual's risk for skin cancer development (see Tables 1 and 2).

\section{Evaluation and Management of Warts and Premalignant Lesions}

Warts, actinic keratoses, and porokeratoses should be treated aggressively at first development.

Early recognition and treatment of these lesions to reduce the burden of viral infection and the extent of early intraepithelial neoplasia may prevent the further

Table 1. Guidelines for the Examination and Follow-Up of OTRs

- Review of systems exam (i.e., constitutional, lungs).

- Full-body skin exam including scalp, genitalia, and feet at least annually. Regional sun-exposed skin exam at other visits.

- Reevaluation of previous sites of NMSC, including regional lymph node exam with attention to the primary drainage basin(s).

- Treat actinic keratoses early.

- Low threshold for skin biopsy-full-thickness biopsy is recommended for definitive diagnosis and histologic evaluation.

- Laboratory and radiologic studies are reserved for patients with signs and symptoms of metastatic disease.

- Patient education with regard to sun exposure and selfexamination of the skin and lymph nodes should be given.

Abbreviations: NMSC, nonmelanoma skin cancer. development of invasive tumors. Accepted treatment modalities also utilized in the general population include:

1. Cryosurgery.

2. Topical 5-fluorouracil.

3. Curettage with electrodesiccation.

Treatment modalities of possible use, but with unanswered concerns for use, in OTRs include, but are not limited to:

1. Topical imiquimod. Safety studies in of imiquimod in OTRs are ongoing. Efficacy studies in OTRs have not been published.

2. Topical photodynamic therapy. Photodynamic therapy may be less useful in the hypertrophic lesions common in OTRs.

3. Ablative skin resurfacing (laser, dermabrasion, chemical peel). The high prevalence of human papillomavirus in OTRs suggests that resurfacing, which creates denuded and reepithelializing skin, may lead to the spread of warts within the area of resurfaced skin.

Prophylactic use of topical retinoid derivatives may decrease the development of additional premalignant lesions. ${ }^{32}$ Adjusting immunosuppression to the lowest level consistent with safely maintaining graft function may also decrease the development of premalignant skin lesions. Adjustment of immunosuppressive medications should only be done in consultation with the patient's primary transplant physician.

Warts, actinic keratoses, and porokeratoses that have an atypical clinical appearance or do not respond to appropriate therapy should be biopsied for histologic evaluation.

It may be difficult to distinguish SCC from warts and premalignant lesions on a clinical basis. ${ }^{33,34}$ 
Table 2. Guidelines for Follow-up Intervals for OTRs*63

Patient Risk Factors

No risk factors except immunosuppression

Risk factors but no history of malignant/premalignant lesions

Actinic keratoses or warts

One basal cell carcinoma

One SCC

Multiple NMSC

High-risk SCC

Metastatic SCC
Frequency of Skin Examination

Initial exam +exam every 12-24 months

Initial exam +exam every 6-12 months

Initial exam + treatment+exam every 3-6 months Initial exam+treatment+exam every 3-6 months Initial exam + treatment+exam every 3-6 months Initial exam + treatment+exam every 3 months Initial exam + treatment+exam every 3 months Initial exam+treatment+exam every 1-3 months

*Because of the increasingly high risk of skin cancer development from the time of transplantation, periodic skin evaluation is recommended for the life of the patient. Abbreviation: NMSC, nonmelanoma skin cancer; SCC, squamous cell carcinoma.

\section{Evaluation and Management of SCC}

\section{All OTRs with suspected or proven SCC should} have a thorough pretreatment evaluation.

Evaluation with notation in the medical record is vitally needed for future study analyses and should include:

1. History of the lesion including duration, rate of growth, prior treatment, and associated pain or tenderness.

2. The size and site of the lesion.

3. Histology of the tumor, including histologic pattern subtype and degree of differentiation, evidence of perineural invasion/inflammation, and measurement of tumor thickness in millimeters (Breslow depth).

4. Examination for presence of cutaneous satellite lesions.

5. Palpation of draining lymph node basins.

6. Full body skin examination including genital and mucosal areas.

Less aggressive SCC in OTRs should be promptly managed with techniques including, but not limited to, destructive modalities and excisional techniques (Figure 2). Histology should be obtained on all lesions.

Characteristics of less aggressive SCC include: ${ }^{11}$

1. Size: $<0.6 \mathrm{~cm}$, "mask" areas of the face (central face, eyelids, eyebrows, periorbital, nose, lips, chin, mandible, preauricular and postauricular areas, temple, and ear), genitalia, hands, and feet.

$<1.0 \mathrm{~cm}$, cheeks, forehead, neck, and scalp.

$<2.0 \mathrm{~cm}$, trunk and extremities.

2. Static or slowly growing.

3. Nonulcerated.

4. Distinct, well-defined clinical margins.

5. Lack of satellite lesions.

6. Histology:

a. In situ.

b. Keratoacanthoma type.

c. Well differentiated.

d. Invasion limited to papillary dermis.

e. Absence of neurotropism.

f. Absence of perivascular or intravascular invasion.

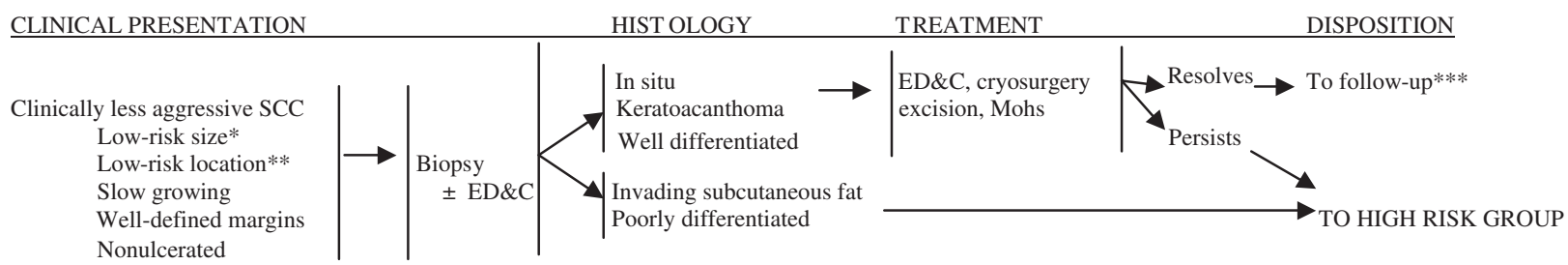

*Size:

$<0.6 \mathrm{~cm}$, "mask" areas of the face (central face, eyelids, eyebrows, periorbital, nose, lips, chin, mandible, preauricular and postauricular areas, temple, and ear),

genitalia, hands, and feet

$<1.0 \mathrm{~cm}$, cheeks, forehead, neck, and scalp

$<2.0 \mathrm{~cm}$, trunk and extremities

**Location NOT on scalp, ear, lip, midface, genitalia, or nail unit or within an anatomic fusion plane

***See Table 2

Figure 2. Management of less aggressive SCC in OTRs. 
Biopsy for histologic exam should be performed before or at the time of treatment. If performed at the time of treatment histologic material should be reviewed to assure that the lesion has characteristics of less aggressive SCC. Tangential excision for histology followed by one of the destructive modalities may be employed. Because OTRs may develop multiple lesions over relatively short periods of time, destructive modalities may be preferred in less aggressive SCC because of the ability to treat multiple lesions at a single setting.

Destructive techniques for treatment of less aggressive SCC in OTRs include:

1. Electrodesiccation and curettage (ED\&C). ED\&C has been shown to be effective in the treatment of selected cutaneous SCC. ${ }^{35}$ Not surprisingly, successful outcome correlated with physician experience in the treatment of basal cell carcinoma. ${ }^{36}$ Based on the higher potential rate of recurrence after ED\&C, ${ }^{37}$ it is suggested that this method may be less effective for SCC located on the high risk area of the head and neck of OTRs.

2. Cryosurgery to $-50^{\circ} \mathrm{C}$ has been shown to be effective treatment for selected SCC. ${ }^{38}$ Combinations of curettage with cryosurgery have also been utilized.

Excisional modalities for the treatment of less aggressive SCC in OTRs include:

1. Mohs micrographic surgery may be considered for moderate risk lesions in anatomic sites where tissue conservation is desired. Mohs micrographic surgery offers very high cure rates while allowing for optimal conservation of normal tissue. ${ }^{37,39,40}$

2. Surgical excision with postoperative margin assessment. In a study by Brodland and $\mathrm{Zitelli}^{41}$ appropri- ate margins of excision of primary cutaneous SCC were formulated on the basis of a prospective study of subclinical microscopic tumor extension. Although margins of $4 \mathrm{~mm}$ were adequate for most SCCs margins of at least $6 \mathrm{~mm}$ were necessary for clearance of tumors with high degree of subclinical extension. On this basis, margins of no less than 4 to $6 \mathrm{~mm}$ of clinically normal skin beyond any surrounding erythema are recommended, where possible, when treating less aggressive SCC in OTRs by standard excision.

Aggressive SCC still confined to the skin and soft tissue in OTRs should be managed promptly with complete removal with excisional techniques (Figure 3). Additional modalities may be helpful in some situations.

Characteristics of SCCs at risk for invasive growth, recurrence, or metastasis in OTRs include: ${ }^{37,42}$

1. Multiple SCC.

2. Size:

$>0.6 \mathrm{~cm}$, "mask" areas of the face (central face, eyelids, eyebrows, periorbital, nose, lips, chin, mandible, preauricular and postauricular areas, temple, and ear), genitalia, hands, and feet;

$>1.0 \mathrm{~cm}$, cheeks, forehead, neck, and scalp;

$>2.0 \mathrm{~cm}$, trunk and extremities.

3. Indistinct clinical borders.

4. Rapid growth.

5. Ulceration.

6. Location on central face, eyelids, eyebrows, periorbital, nose, lips, chin, mandible, preauricular and postauricular areas, temple and ear, genitalia, and digits.

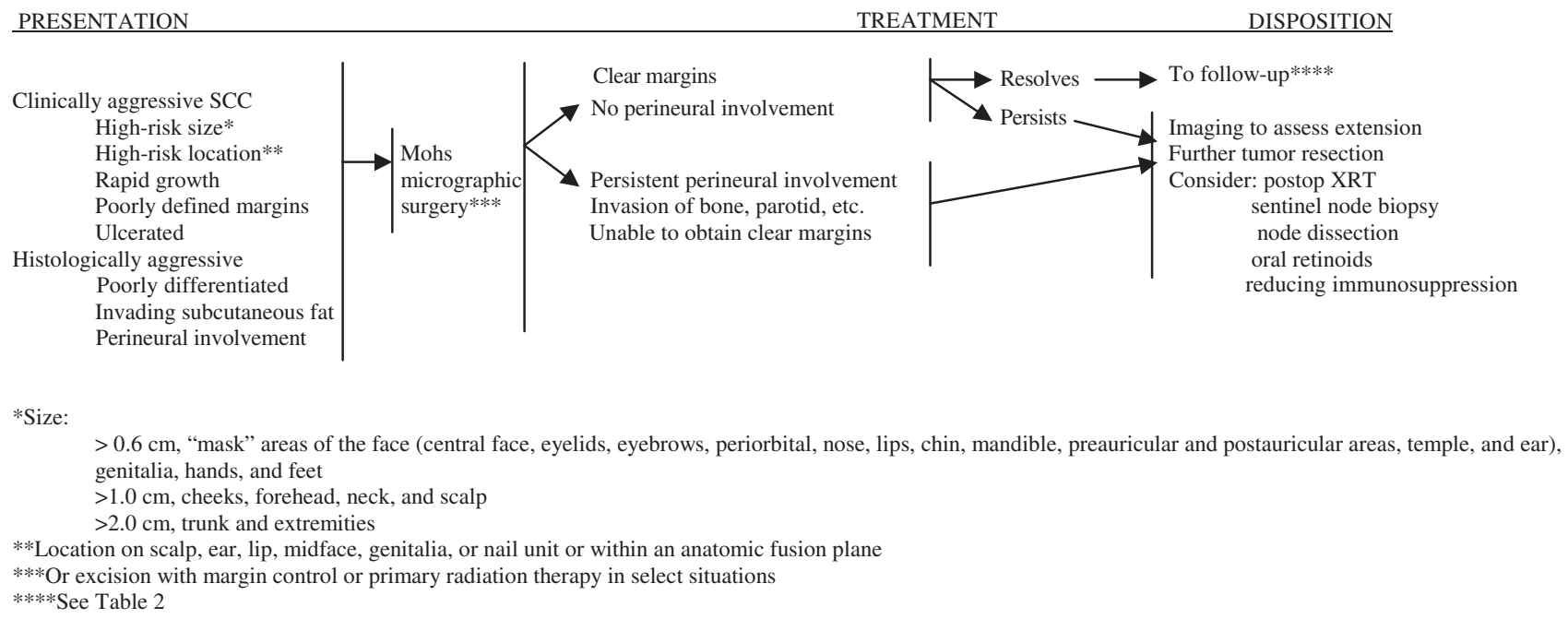

Figure 3. Management of aggressive SCC without lymphadenopathy or satellite metastasis in OTRS. 
7. Occurrence in a scar, in an area of chronic inflammation, or in the field of prior radiation therapy.

8. Recurrent after previous treatment.

9. Presence of satellite lesions.

10. Histology:

a. Deep extension of tumor into the subcutaneous fat;

b. Perineural invasion/inflammation;

c. Perivascular or intravascular invasion;

d. Poor differentiation.

Excisional modalities for the treatment of aggressive SCC in OTRs include:

1. Mohs micrographic surgery offers the highest cure rates and optimal conservation of normal tissue in selected NMSC including SCC. ${ }^{37,39,40}$ Local control rates achieved with Mohs surgery are very high in primary SCC, recurrent SCC, and high-risk SCC.

2. Excision with intraoperative frozen section control may also result in high cure rates when performed by a surgeon and pathologist with expertise and experience in the procedure.

3. Excision with postoperative margin assessment may be considered if Mohs micrographic surgery or excision with intraoperative frozen section control is not available, if the lesion is of such a size that complete intraoperative margin evaluation is not practical, if the lesion is of such a size or depth that excision under local anesthesia is not feasible, if the patient has significant comorbidities requiring monitored anesthesia, or if tissue conservation is not an issue. Margins of at least 6 to 10 $\mathrm{mm}$ beyond any surrounding erythema and resection into the subcutaneous fat are recommended. ${ }^{37}$ Frozen section analysis of selected margins may be useful.

Additional modalities include:

1. Radiation therapy can be considered as a primary modality for inoperable tumors and in patients unable to tolerate surgical excision. ${ }^{43}$ Although radiation therapy can be a valuable primary modality for selected tumors, the primary difficulties in OTRs lie in the lack of margin control and the tendency of OTRs to develop multiple, often adjacent tumors. Adjunctive radiation treatment should be considered in the following circumstances:

a. Inability to achieve margins clear of invasive tumor by surgery;

b. Presence of substantial perineural invasion/inflammation. ${ }^{44-48}$
2. Sentinel lymph node biopsy (SLNB) is not currently used routinely in the evaluation of high risk SCC. Recent small studies, however, are beginning to support a potential role for SLNB in evaluation of high risk NMSC. In one study, ${ }^{49} 20$ patients with T2 (size $>2 \mathrm{~cm}$ ) SCCs on the lower lip underwent SLNB with the sentinel node identified in 18 (90\%). Nodal disease was identified in 3 of these patients $(18.8 \%)$. The role of SLNB in evaluation of higher risk SCCs in OTRs remains to be completely defined. SLNB may be considered in cases higher risk SCC, but usually should be reserved for clinical research settings and selected situations at centers with expertise and experience in SLNB.

3. Chemoprophylaxis with oral retinoids (acetretin, etretinate, isotretinoin) has been effective in reducing the development of skin cancers and premalignant lesions in OTRs with multiple skin lesions. ${ }^{50-53}$ The effect is not absolute and some tumors continue to develop during therapy. The effect is not durable after cessation of the drug. When the retinoid is discontinued, a rebound is almost always noted with the rate of new lesion formation matching or exceeding the pretreatment rate. Many patients are unable to tolerate the side effects of oral retinoids on a long-term basis. Blood chemistries including liver function studies and lipid levels must be monitored. The teratogenicity of oral retinoids dictates that extreme caution is necessary when these drugs are administered to women of childbearing potential. There are no long-term safety studies of the use of oral retinoids in OTRs.

4. Excision and split-thickness skin grafting of the dorsa of the hand and forearm has been utilized for the treatment of multiple SCC of these areas with good results. The grafted area remains tumor-free for an extended period of time. The procedure has significant morbidity and entails a significant recovery period. ${ }^{54-56}$

5. Decreasing immunosuppression should be considered in cases of life-threatening skin cancers in OTRs and the rapid development of multiple SCCs in OTRs. There are reports of decreased internal cancers with low-dose rather than high-dose cyclosporine $^{22}$ as well as decreased skin cancers in a small series of patients in whom immunosuppressive medications were discontinued. ${ }^{57}$ Certain organ grafts may survive gradual and complete weaning of immunosuppression, presumably through population of the host with immunosuppressive $\mathrm{T}$ cells originating from the graft. ${ }^{42,58-60}$ The decision to reduce immunosuppression must be made in consultation with the patient's transplant physician. 


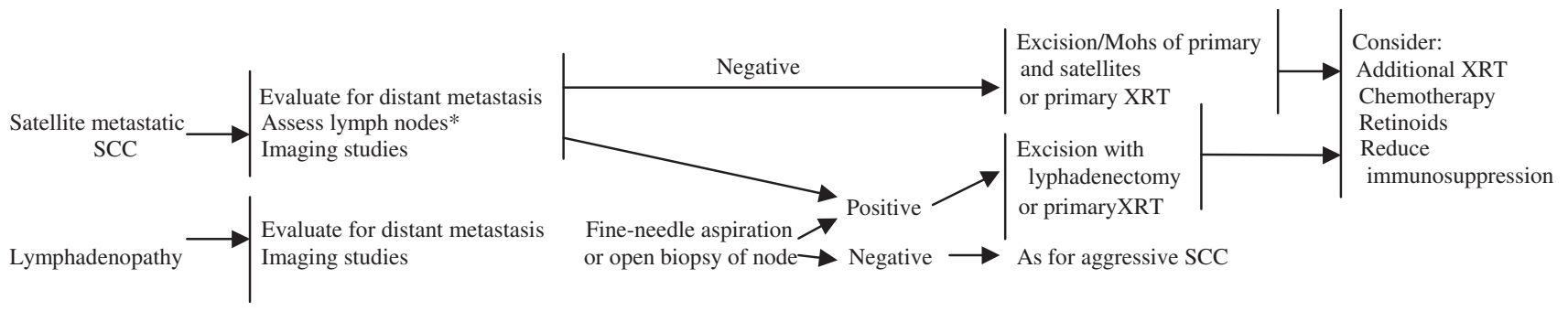

*Role for sentinel lymph node biopsy in SCC is not defined

Figure 4. Management of SCC with lymphadenopathy or satellite metastasis in OTR (in conjunction with medical, surgical, and radiological oncology).

Satellite lesions (in-transit cutaneous metastases) of $S C C$ in OTRs require additional therapy and evaluation (Figure 4).

1. A complete oncologic evaluation should be performed to exclude the presence of distant metastases.

2. For satellite lesions, which present with the primary tumor, consider standard excision with margins of 0.5 to $1 \mathrm{~cm}$ or Mohs micrographic surgery of primary and satellite lesions followed by consideration for postoperative radiation therapy.

3. For satellite lesions that present subsequent to the treatment of a primary cancer, excision of the metastatic lesion(s) followed by radiation therapy or primary radiation therapy may be considered.

4. Retinoid chemoprophylaxis may be considered. See above.

5. Decreasing the dose of immunosuppressive agents should be considered. See above.

OTRs with SCC and palpable lymphadenopathy or extensive tumor spread should be treated in the same manner as nonimmunosuppressed patients with additional attention to reducing immunosuppression and chemoprophylaxis. ${ }^{61}$

1. The finding of lymphadenopathy in an OTR with a high-risk SCC should result in prompt referral to an appropriate specialist for fine-needle aspiration and/or open lymph node biopsy.

2. A complete oncologic evaluation should be performed to exclude the presence of distant metastases.

3. Therapeutic lymphadenectomy is indicated for tumors involving the lymph node basin.

4. Adjunctive radiation therapy should be considered, especially for head and neck tumors.

5. Parotidectomy and adjunctive radiotherapy should be considered for aggressive head and neck tumors involving the parotid. ${ }^{62}$
6. Retinoid chemoprophylaxis should be considered. See above.

7. Decreasing the dose of immunosuppressive agents may be considered. See above.

With all evaluation, prevention, and treatment strategies, a collaborative approach between transplant physicians, dermatologists, oncologic surgeons, pathologists, medical oncologists, and radiation oncologists with experience with aggressive tumors in OTRs is optimal. ${ }^{63}$

\section{Summary}

The increased incidence of SCC in OTRs is a major cause of morbidity and mortality in a select group of patients. Unfortunately, there are few prospective, controlled studies concerning the prevention and treatment of SCC in OTRs and limited observational studies have been published. Theses guidelines are based on the best currently available data and the experience of the authors and other members of ITSCC. The guidelines are designed to provide guidance and not prescribe treatment for individual patients. Hopefully, they will stimulate further study of this problem. The guidelines will require continuous modification as additional, more rigorous studies and experience become available.

\section{References}

1. Bavinck JN, Vermeer B, Van der Woude FJ, et al. Relation between skin cancer and HLA antigens in renal-transplant recipients. N Engl J Med 1991;325:843-8.

2. Espana A, Redondo P, Fernandez AL, et al. Skin cancer in heart transplant recipients [review]. J Am Acad Dermatol 1995;32: 458-65.

3. Euvrard S, Kanitakis J, Claudy A. Skin cancers after organ transplantation [review]. N Engl J Med 2003;348:1681-91.

4. Jensen P, Hansen S, Moller B, et al. Skin cancer in kidney and heart transplant recipients and different long-term immunosuppressive therapy regimens. J Am Acad Dermatol 1999;40:177-86.

5. Penn I, First MR. Merkel's cell carcinoma in organ recipients. report of 14 cases. Transplantation 1999;68:1717-21. 
6. Blohme I, Larko O. Skin lesions in renal transplant patients after 1023 years of immunosuppressive therapy. Acta Derm Venereol 1990; 70:491-4.

7. Taylor AEM, Shuster S. Skin cancer after renal transplantation: the causal role of azathioprine. Acta Derm Venereol 1992;72:115-9.

8. Bouwes Bavinck JN, Hardie DR, Green A, et al. The risk of skin cancer in renal transplant recipients in Queensland, Australia: a follow-up study. Transplantation 1996;61:715-21.

9. Penn I. Tumors after renal and cardiac transplantation. Hematol Oncol Clin North Am 1993; 7:431-45.

10. Ong CS, Keogh AM, Kossard S, Macdonald PS, Spratt PM. Skin cancer in Australian heart transplant recipients. J Am Acad Dermatol 1999;40:27-34.

11. Miller SJ. The National Comprehensive Cancer Network (NCCN) guidelines of care for nonmelanoma skin cancers. Dermatol Surg 2000;26:289-92.

12. Guidelines of care for cutaneous squamous cell carcinoma. Committee on Guidelines of Care. Task Force on Cutaneous Squamous Cell Carcinoma. J Am Acad Dermatol 1993;28:628-31.

13. EBPG Expert Group on Ranal Transplantation. European best practice guidelines for renal transplantation. Section IV: Long-term management of the transplant recipient. IV.6.2. Cancer risk after renal transplantation. Skin cancers: prevention and treatment. Nephrol Dial Transplant 2002;17(Suppl 4):31-6.

14. Grabbe S, Granstein RD. Mechanisms of ultraviolet radiation carcinogenesis [review]. Chem Immunol 1994;58:291-313.

15. Ferrandiz C, Fuente MJ, Ribera M, et al. Epidermal dysplasia and neoplasia in kidney transplant recipients. J Am Acad Dermatol 1995; 33:590-6.

16. Liddington M, Richardson AJ, Higgins RM, et al. Skin cancer in renal transplant recipients. Br J Surg 1989;76:1002-5.

17. Danpanich E, Kasiske BL. Risk factors for cancer in renal transplant recipients [comment]. Transplantation 1999;68:1859-64.

18. Mithoefer AB, Supran S, Freeman RB. Risk factors associated with the development of skin cancer after liver transplantation. Liver Transplant 2002;8:939-44.

19. Penn I. Neoplastic complications of transplantation. Semin Respir Infect 1993;8:233-9.

20. Ramsay HM, Fryer AA, Reece S, Smith AG, Harden PN. Clinical risk factors associated with nonmelanoma skin cancer in renal transplant recipients. Am J Kidney Dis 2000;36:167-76.

21. Jensen P, Hansen S, Moller B, et al. Are renal transplant recipients on CsA-based immunosuppressive regimens more likely to develop skin cancer than those on azathioprine and prednisolone? Transplant Proc 1999;31-1120.

22. Dantal J, Hourmant M, Cantarovich D, et al. Effect of long-term immunosuppression in kidney-graft recipients on cancer incidence: randomised comparison of two cyclosporin regimens [see comments]. Lancet 1998;351:623-8.

23. Shamanin V, zur Hausen $H$, Lavergne D, et al. Human papillomavirus infections in nonmelanoma skin cancers from renal transplant recipients and nonimmunosuppressed patients [see comments]. J Natl Cancer Inst 1996;88:802-11.

24. Leigh IM, Buchanan JA, Harwood CA, Cerio R, Storey A. Role of human papillomaviruses in cutaneous and oral manifestations of immunosuppression. J Acquir Immune Defic Syndr 1999;21 (Suppl 1): S49-57.

25. Ducloux D, Carron PL, Rebibou JM, et al. CD4 lymphocytopenia as a risk factor for skin cancers in renal transplant recipients. Transplantation 1998;65:1270-2.

26. Thompson SC, Jolley D, Marks R. Reduction of solar keratoses by regular sunscreen use [comment]. N Engl J Med 1993;329:1147-51.

27. Naylor MF, Boyd A, Smith DW, et al. High sun protection factor sunscreens in the suppression of actinic neoplasia. Arch Dermatol 1995;131:170-5.

28. Green A, Williams G, Neale R, et al. Daily sunscreen application and betacarotene supplementation in prevention of basal-cell and squamous-cell carcinomas of the skin: a randomised controlled trial [comment] [published erratum appears in Lancet 1999;18:1038]. Lancet 1999;354:723-9.

29. Butt A, Roberts DL. Renal transplant recipients and protection from sun: need for education. Lancet 1997;349:179-80.
30. Cowen EW, Billingsley EM. Awareness of skin cancer by kidney transplant patients. J Am Acad Dermatol 1999;40:697-701.

31. Seukeran DC, Newstead CG, Cunliffe WJ. The compliance of renal transplant recipients with advice about sun protection measures. $\mathrm{Br}$ J Dermatol 1998;138:301-3.

32. Euvrard S, Verschoore M, Touraine J, et al. Topical retinoids for warts and keratoses in transplant recipients. Lancet 1992;340:48.

33. Blessing K, McLaren KM, Benton EC, et al. Histopathology of skin lesions in renal allograft recipients-an assessment of viral features and dysplasia. Histopathology 1989;14:129-39.

34. King GN, Healy CM, Glover MT, et al. Increased prevalence of dysplastic and malignant lip lesions in renal-transplant recipients. N Engl J Med 1995;332:1052-7.

35. Goldman G. The current status of curettage and electrodesiccation [review]. Dermatol Clin 2002;20:569-78; ix.

36. Kopf AW, Bart RS, Schrager D, Lazar M, Popkin GL. Curettageelectrodesiccation treatment of basal cell carcinomas. Arch Dermatol 1977;113:439-43.

37. Rowe DE, Carroll RJ, Day CL Jr. Prognostic factors for local recurrence, metastasis and survival rates in squamous cell carcinoma of the skin, ear, and lip. Implications for treatment modality selection [comment] [review]. J Am Acad Dermatol 1992; 26:976-90.

38. Sinclair RD, Dawber RP. Cryosurgery of malignant and premalignant diseases of the skin: a simple approach [review]. Australas J Dermatol 1995;36:133-42.

39. Nguyen TH, Ho DQ. Nonmelanoma skin cancer [review]. Curr Treat Opt Oncol 2002;3:193-203.

40. Leslie DF, Greenway HT. Mohs micrographic surgery for skin cancer [review]. Australas J Dermatol 1991;32:159-64.

41. Brodland DG, Zitelli JA. Surgical margins for excision of primary cutaneous squamous cell carcinoma. J Am Acad Dermatol 1992; $27: 241-8$.

42. Euvrard S, Kanitakis J, Pouteil-Noble C, et al. Aggressive squamous cell carcinomas in organ transplant recipients. Transplant Proc 1995; 27:1767-8.

43. Morrison WH, Garden AS, Ang KK. Radiation therapy for nonmelanoma skin carcinomas [review]. Clin Plast Surg 1997;24: 719-29.

44. Mendenhall WM, Parsons JT, Mendenhall NP, et al. Carcinoma of the skin of the head and neck with perineural invasion. Head Neck 1989;11:301-8.

45. McCord MW, Mendenhall WM, Parsons JT, Flowers FP. Skin cancer of the head and neck with incidental microscopic perineural invasion. Int J Radiat Oncol Biol Phys 1999;43:591-5.

46. McCord MW, Mendenhall WM, Parsons JT, et al. Skin cancer of the head and neck with clinical perineural invasion. Int J Radiat Oncol Biol Phys 2000;47:89-93.

47. Williams LS, Mancuso AA, Mendenhall WM. Perineural spread of cutaneous squamous and basal cell carcinoma. CT and MR detection and its impact on patient management and prognosis. Int J Radiat Oncol Biol Phys 2001;49:1061-9.

48. Mendenhall WM, Amdur RJ, Williams LS, et al. Carcinoma of the skin of the head and neck with perineural invasion [review]. Head Neck 2002;24:78-83.

49. Altinyollar H, Berberoglu U, Celen O. Lymphatic mapping and sentinel lymph node biopsy in squamous cell carcinoma of the lower lip. Eur J Surg Oncol 2002;28:72-4.

50. Rook AH, Jaworsky C, Nguyen T, et al. Beneficial effect of lowdose systemic retinoid in combination with topical tretinoin for the treatment and prophylaxis of premalignant and malignant skin lesions in renal transplant recipients. Transplantation 1995;59: 714-9.

51. Yuan ZF, Davis A, Macdonald K, Bailey RR. Use of acitretin for the skin complications in renal transplant recipients. N Z Med J 1995; 108:255-6.

52. Kelly JW, Sabto J, Gurr FW, Bruce F. Retinoids to prevent skin cancer in organ transplant recipients. Lancet 1991;338:1407.

53. Bavinck JN, Tieben LM, Van der Woude FJ, et al. Prevention of skin cancer and reduction of keratotic skin lesions during acitretin therapy in renal transplant recipients: a double-blind, placebocontrolled study. J Clin Oncol 1995;13:1933-8. 
54. Glover MT, Niranjan N, Kwan JT, Leigh IM. Non-melanoma skin cancer in renal transplant recipients: the extent of the problem and a strategy for management. Br J Plast Surg 1994;47:86-9.

55. Scholtens RE, van Zuuren EJ, Posma AN. Treatment of recurrent squamous cell carcinoma of the hand in immunosuppressed patients. J Hand Surg Am 1995;20:73-6.

56. van Zuuren EJ, Posma AN, Scholtens REM, et al. Resurfacing the back of the hand as treatment and prevention of multiple skin cancers in kidney transplant recipients. J Am Acad Dermatol 1994; $31: 760-4$.

57. Otley CC, Coldiron BM, Stasko T, Goldman GD. Decreased skin cancer after cessation of therapy with transplant-associated immunosuppressants. Arch Dermatol 2001;137:459-63.

58. Ramos HC, Reyes J, Abu-Elmagd K, et al. Weaning of immunosuppression in long-term liver transplant recipients. Transplantation 1995;59:212-7.
59. Mazariegos GV, Reyes J, Marino I, et al. Risks and benefits of weaning immunosuppression in liver transplant recipients: longterm follow-up. Transplant Proc 1997;29:1174-7.

60. Mazariegos GV, Reyes J, Marino IR, et al. Weaning of immunosuppression in liver transplant recipients. Transplantation 1997;63: 243-9.

61. Martinez JC, Otley CC, Stasko T, et al. Defining the clinical course of metastatic skin cancer in organ transplant recipients: a multicenter collaborative study. Arch Dermatol 2003;139: 301-6.

62. Lai SY, Weinstein GS, Chalian AA, Rosenthal DI, Weber RS. Parotidectomy in the treatment of aggressive cutaneous malignancies. Arch Otolaryngol Head Neck Surg 2002;128:521-6.

63. Otley CC. Organization of a specialty clinic to optimize the care of organ transplant recipients at risk for skin cancer. Dermatol Surg 2000;26:709-12. 